\title{
Transoral Transtonsillar Styloidectomy: A Minimally Invasive Technique for Stylohyoid Syndrome
}

\author{
Sudhir M Naik ${ }^{1}$, Sarika S Naik²
}

\begin{abstract}
Background/objective: Transtonsillar styloidectomy is the most common surgical approach for symptom complex of styalgia. It is a minimally invasive procedure of excision of the symptomatic elongated process and remains the most preferred procedure.

Materials and methods: Transoral transtonsillar styloidectomy done in 23 symptomatic cases had relief of symptoms with some needing adjuvant treatment with carbamazepine or gabapentin.

Conclusion: Symptoms subside over a period of months and depend on the pathology of the syndrome, which is still to be investigated in detail. The symptoms depend of the effects of the elongated process on the nerves and over internal carotid artery rather than the length itself. Keywords: 3D CT scan, Stylohyoid syndrome, Superior constrictor, Transoral styloidectomy. International Journal of Head and Neck Surgery (2020): 10.5005/jp-journals-10001-1384
\end{abstract}

\section{INTRODUCTION}

Transtonsillar styloidectomy is the commonest surgical approach for symptom complex of styalgia. ${ }^{1,2}$ The symptom complex provides an enigma for the otorhinolaryngologists as the length of the process, causing symptoms vary among many literature searches done among the past decade. ${ }^{1,2}$ Radiologists hardly agree with the proportionality of the length with the symptom complex defined by the surgeons. ${ }^{1,2}$ Hence after decades of research on the topic, the symptom complex is not well defined as far as the proportionality of symptoms, and the length of the styloid process is concerned. ${ }^{1,2}$ Symptom complex due to styloid enlargement manifests as a classical styloid syndrome and the rarer stylocarotid syndrome. ${ }^{1,2}$ The classical syndrome manifests as pain in the tonsillar fossa over the post-tonsillectomy scar and rarely as dysphagia, odynophagia, hypersalivation, foreign body sensation, and more rarely by temporary voice change. ${ }^{1,2}$ The rarer stylocarotid syndrome is not associated with tonsillectomy but presents as persistent pain radiating along the carotid in the tonsillar fossa., ${ }^{1,2}$ The stylohyoid apparatus compresses the internal or the external carotid arteries and especially their perivascular sympathetic fibers causing tonsillar pain., ${ }^{1,2}$

\section{Materials and Methods}

We report 23 cases presenting with an elongated styloid process with symptoms of styalgia with 12 females and 11 males. All presented with a history of pain and foreign body sensation in the throat. None had any acute exacerbation, whereas eight patients had tonsillectomy done earlier. On palpation of the tonsillar fossa, the prick was felt, and the patient recognized the same pain for symptoms. We followed the widely practiced method of palpation of the tonsillar fossa in patients with clinical features of styalgia. The fossa was palpated, and a prick felt with the gloved finger, which was later investigated by classical X-ray townes, and lateral view skull base. They were later confirmed by 3D CT reconstruction of the skull base (Figs 1 and 2).

All cases were done transoral tonsillar fossa technique with dissection snare tonsillectomy and bipolar cauterization with
1Department of ENT and Head and Neck Surgery, The Oxford Medical College Hospital and Research Centre, Yadavanahalli, Bengaluru, Karnataka, India

${ }^{2}$ Department of Anesthesia and Critical Care, The Oxford Medical College Hospital and Research Centre, Yadavanahalli, Bengaluru, Karnataka, India

Corresponding Author: Sudhir M Naik, Department of ENT and Head and Neck Surgery, The Oxford Medical College Hospital and Research Centre, Yadavanahalli, Bengaluru, Karnataka, India, Phone: +91 9590000500, e-mail: sud223@gmail.com

How to cite this article: Naik SM, Naik SS. Transoral Transtonsillar Styloidectomy: A Minimally Invasive Technique for Stylohyoid Syndrome. Int J Head Neck Surg 2020;11(2):23-25.

Source of support: Nil

Conflict of interest: None

general anesthesia. The styloid protuberance identified by digital palpation was incised from the overlying mucosa, superior constrictor dissected, and the tip of styloid skeletonized, releasing

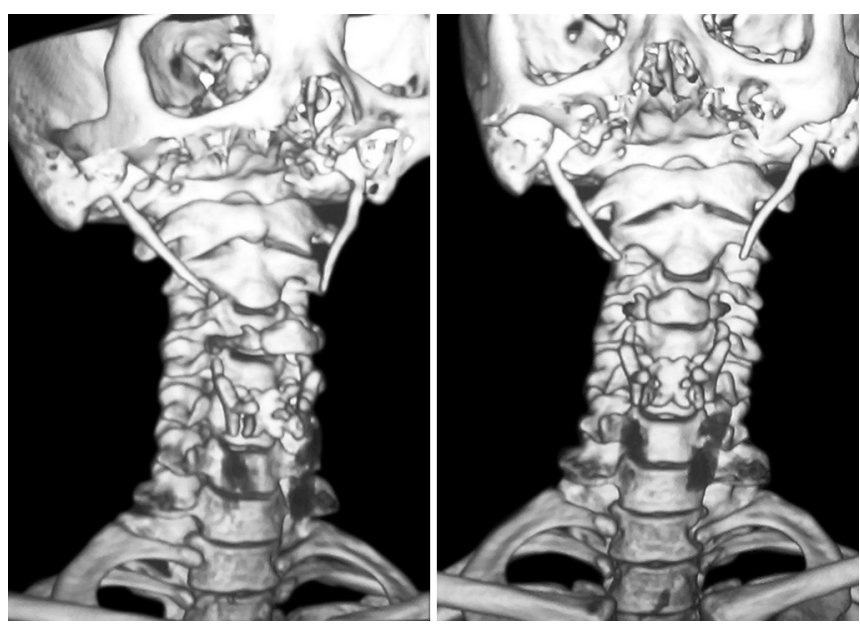

Fig. 1: 3D reconstructed CT images of elongated styloid process

(c) The Author(s). 2020 Open Access This article is distributed under the terms of the Creative Commons Attribution 4.0 International License (https://creativecommons. org/licenses/by-nc/4.0/), which permits unrestricted use, distribution, and non-commercial reproduction in any medium, provided you give appropriate credit to the original author(s) and the source, provide a link to the Creative Commons license, and indicate if changes were made. The Creative Commons Public Domain Dedication waiver (http://creativecommons.org/publicdomain/zero/1.0/) applies to the data made available in this article, unless otherwise stated. 


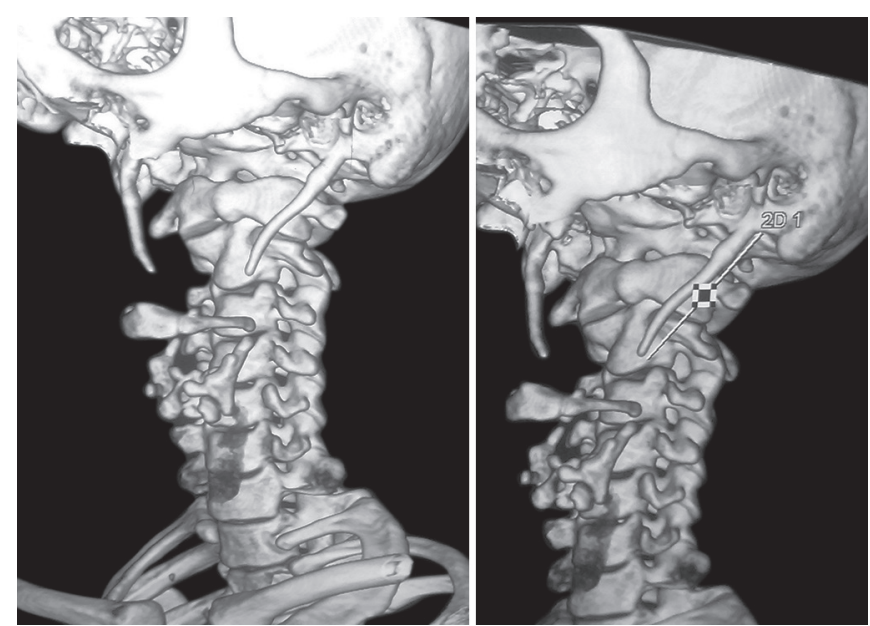

Fig. 2: 3D reconstructed $C T$ images measuring the length of styloid process

the muscles and ligaments attached to it. The split muscle bed is cleaned by povidone-iodine solution, and the superior constrictor muscle closed by 3-0 vicryl. No more suturing is done in the tonsillectomy method. But in the anterior pillar incision method, the pillar is closed with the same 3-0 vicryl at the mucosal reflection onto the tonsils. The procedure was repeated in the other fossa in bilateral cases with the normal postoperative protocol as of tonsillectomy with oral antibiotics and anti-inflammatory drugs for 7 days at discharge (Fig. 3).

\section{Discussion}

Initially, the styloid symptom complex was defined as elongation more than $25 \mathrm{~mm}$ in length later recently consensus has been arrived for the length of $30 \mathrm{~mm}^{3}$ The incidence of the stylohyoid syndrome is $4-7 \%$, while the irony is only a meager $4 \%$ of the patients have the classical symptom complex. ${ }^{4,5}$ So the overall incidence is less than $1 \%$ seen mostly in the third and fourth decade. ${ }^{5,6}$ The length, diversion, and compression effects of the elongated styloid process give rise to symptoms in patients with the palpable process in the tonsillar fossa. ${ }^{3-6}$

Stylohyoid complex consists of the styloid process, stylohyoid ligament, and lesser horn of hyoid bone derived from the 2nd branchial arch of Reichert cartilage with the process arising from temporal bone just anteromedial to the stylomastoid foramen. ${ }^{3-6}$ Three muscles, i.e., styloglossus, stylohyoid, stylopharyngeus, and two ligaments, i.e., stylohyoid and stylomandibular ligament attached to the styloid process lying beside important neurovascular structure in the neck, i.e., $v$, vii, ix, x, xi, xii cranial nerves, and internal jugular vein. ${ }^{6,7}$ The tip of styloid usually lies between internal and external carotid arteries, and its angulation (medial, lateral, anterior, or posterior) and length cause symptoms, respectively. ${ }^{6,7}$ The anterior angulation and ossification of the ligament are responsible for symptoms like persistent throat pain, foreign body sensation, dysphagia, odynophagia, chronic neck pain, headache, and referred otalgia. ${ }^{8}$

Symptoms are often vague with pain in the throat, facial pain, referred otalgia, and dysphagia, while elongated styloid is seen in $4 \%$ of the population while less than $10 \%$ are symptomatic., ${ }^{9,10}$ Also postulated are proliferation of granulation tissue after a traumatic fracture of styloid process insertion tendinosis or impingement on the carotid vessels as well as the glossopharyngeal, lower branch of trigeminal and the chorda tympani. ${ }^{11,12}$ The proposed etiopathology

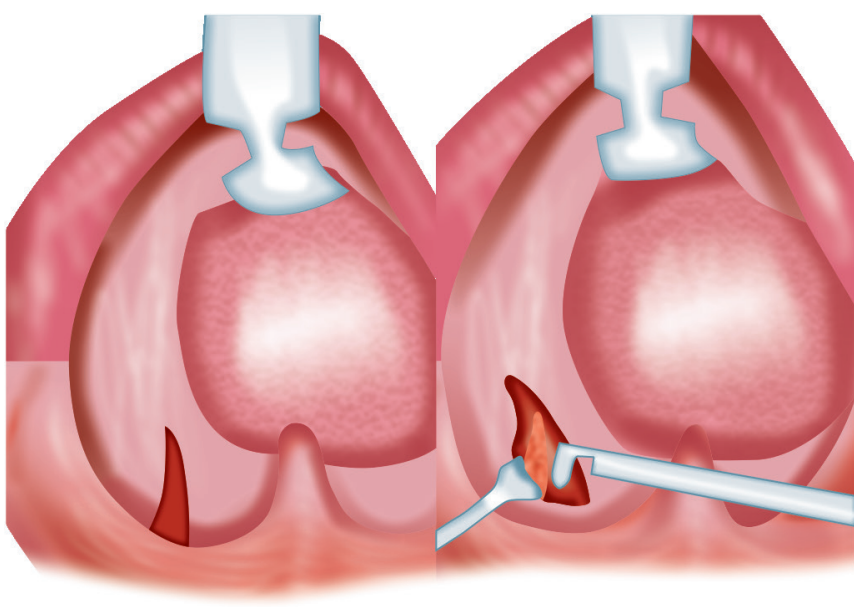

Fig. 3: Diagrammatic representation of minimally invasive transtonsillar approach

includes surgical trauma or local chronic irritation that can lead to osteitis and periostitis of styloid complex with consequent reactive ossifying hyperplasia leading to pressure symptoms. ${ }^{1,13}$ Here, the glossopharyngeal nerve may be compressed, degenerative and inflammatory insertion tendinitis, irritation of pharyngeal mucosa and v, vii, ix, and $x$ cranial nerves by fibrosis of post-tonsillectomy scar, as well as sympathetic nerve irritation due to impingement on carotids. ${ }^{1,13}$ Elongated styloid process is a differential diagnosis of temporomandibular joint (TMJ) disorder. ${ }^{14}$ This causes pain in the TMJ region or preauricular region, mandibular movements, joint noises and sounds, referred pain, headaches, tinnitus, earaches, vertigo or dizziness, and hyperacusis. ${ }^{14}$

The CT is the diagnostic method of choice for symptomatic styalgia; screening can be done by panoramic radiographs and ultrasound. ${ }^{15,16} 3 \mathrm{D}-\mathrm{CT}$ reconstruction of images accurately makes the length of the process, direction, and anatomical relation to adjacent tissues. ${ }^{17}$ The patient can be explained by the disease and the planned surgery. ${ }^{17}$ DD reconstruction gives a length of $30 \mathrm{~mm}$, to be normal and all above it is considered abnormal if the symptoms are suggestive. ${ }^{15,16}$ These reconstructed images classify the styloid elongation into three types, type I represents uninterrupted elongated styloid process, type II represents a styloid process apparently being joined to the stylohyoid ligament by a single pseudo-articulation (articulated elongated styloid process) while type III consists of interrupted segments of the mineralized ligament, creating the appearance of multiple pseudo-articulations within the ligament. ${ }^{18}$

The surgical approaches include an external (transcervical) and an internal (transoral). ${ }^{13}$ An extraoral surgical approach reduces the damage caused to the surrounding tissues and nerves that could occur during the operation due to less anatomic exposure and intraoral commensals. ${ }^{19}$ The incision here extends the mastoid process along the sternocleidomastoid to the level of the hyoid then up across the neck to the midline of the chin, which can give rise to the scar for benign disease and rarely damage to cutaneous nerves. ${ }^{2,3}$ Persistence of symptoms after adequate surgical excision is seen in $20 \%$ of cases, which is explained as glossopharyngeal nerve being entrapped in the fibrous tissue or the cut end of inadequately shortened styloid process irritating the overlying bed of the tonsillar fossa. ${ }^{7}$

Endoscopic visualization to help visualization of small vessels nerves and other anatomically important structures are reported. ${ }^{17}$ 
But the transoral approach takes advantage of the elastic tonsillar bed against the stable styloid process, which pierces through the muscle to pop out hardly any bleeders and nerves are encountered. ${ }^{17}$ The dissection is just confined to the tip of the process and skeletonizing it and no blind dissection. We used $2.5 \times$ prismatic loupes for magnification and depth perception. Palpation of the process and dissecting at the tip reduces inadvertent exposure of the fossa and reduces the chances of neck space infection. Also, the transoral approach is for styloidectomy only, and no attempt at visualization of the nerves or other soft tissues is made, which reduces postoperative complication, pain, and fastens recovery.

\section{Conclusion}

Transoral styloidectomy is a minimally invasive procedure aided with magnification, and better illumination becomes the procedure of choice for the stylohyoid syndrome. Symptoms subside over a period of months and depend on the pathology of the syndrome, which is still to be investigated in detail. The symptoms depend on the effects of the elongated process on the nerves and over internal carotid artery rather than the length itself.

\section{References}

1. Purushothaman PK, Ramakrishnan R, Vikram PSJ. An Innovative Technique of Transoral Resection of the Styloid Process in Eagles Syndrome Using Kerrison Punch. Int J Sci Res Publ 2013 Jun;3(6): $1-3$.

2. Naik SM, Naik SS. Tonsillo-Styloidectomy for Eagle's Syndrome: A Review of 15 Cases in KVG Medical College Sullia. Oman Med J 2011 Mar;26(2):122-126. DOI: 10.5001/omj.2011.30.

3. Baharudin A, Rohaida I, Khairudin A. Transoral Surgical Resection of Bilateral Styloid Processes Elongation (Eagle's Syndrome). Acta Inform Med 2012 Jun;20(2):133-135. DOI: 10.5455/aim.2012.20. 133-135.

4. Chourdia V. Elongated Styloid process (Eagle's Syndrome) \& Severe Headache. Indian J Otolaryngol Head Neck Surg 2002;54(3):238-241. DOI: 10.1007/BF02993114.

5. Prasad KC, Kamath MP, Reddy KJ, et al. Elongated Styloid Process (Eagle's Syndrome): A Clinical study. J Oral Maxillofac Surg 2002;60:171-175. DOI: 10.1053/joms.2002.29814.
6. Beder E, Ozgursoy OB, Ozgursoy SK. Current Diagnosis and Transoral Surgical Treatment of Eagle's Syndrome. J Oral Maxillofac Surg 2005;63:1742-1745. DOI: 10.1016/j.joms.2005.08.017.

7. Gosh LM, Dubey SP. The syndrome of elongated styloid process. Auris Nasus Larynx 1999;26:169-175. DOI: 10.1016/s0385-8146(98)00079-0.

8. Yavuz H, Caylakli F, Yildirim T, et al. Angulation of the styloid process in Eagle's Syndrome. Eur Arch Otorhinolarongol 2008;265:1393-1396. DOI: 10.1007/s00405-008-0686-9.

9. Mortellaro C, Biancucci P, Picciolo G, et al. Eagle's syndrome: importance of a corrected diagnosis and adequate surgical treatment. J Craniofac Surg 2002;13:755-758. DOI: 10.1097/00001665200211000-00007.

10. Savranlar A, Uzun L, Ugur MB, et al. Three-dimensional CT of Eagle'sThree-dimensional CT of Eagle's syndrome. Diagn Interv Radiol 2005;11:206-209.

11. Murtagh RD, Caracciolo JT, Fernandez G. CT Findings Associated with Eagle Syndrome. AJNR Am J Neuroradiol 2001;22:1401-1402.

12. Balbuena L, Hayes D, Ramirez SG. Eagle's syndrome (elongated styloid process). South Med J 1997;90(3):331-334. DOI: 10.1097/00007611199703000-00014.

13. Diamond LH, Cottrell DA, Hunter MJ, et al. Eagle's Syndrome: A Report of 4 Patients Treated Using a Modified Extraoral Approach. J Oral Maxillofac Surg 2001;59:1420-1426. DOI: 10.1053/joms.2001. 28276.

14. de Andrade KM, Rodrigues CA, Watanabe PC, et al. Styloidprocess elongation and calcification in subjects with tmd: clinical andradiographic aspects. Braz Dent J 2012;23(4):443-450.

15. Müderris $T$, Bercin S, Sevil E, et al. Surgical management ofelongated styloid process: intraoral or transcervical? Eur Arch Otorhinolaryngol 2013;271(6):1709-1713. DOI: 10.1007/s00405-0132664-0.

16. Nayak DR, Pujary K, Aggarwal M, et al. Role of three-dimensional computed tomography reconstruction in the managementof elongated styloid process: a preliminary study. J Laryngol Otol 2007;121(4):349-353. DOI: 10.1017/S0022215106003276.

17. Matsumoto F, Kase K, Kasai M, et al. Endoscopy-assisted transoral resection of the styloid process in Eagle's syndrome. Head Face Med 2012;8:21. DOI: 10.1186/1746-160X-8-21.

18. Langlais RP, Miles DA, Van Dis ML. Elongated andmineralized stylohyoid ligament complex: a proposed classification and report of a case of Eagle's syndrome. Oral Surg Oral Med Oral Pathol 1986;61:527-532. DOI: 10.1016/0030-4220(86)90400-7.

19. Thoenissen $P$, Bittermann $G$, Schmelzeisen R, et al. Eagle's syndromeA non-perceived differential diagnosis oftemporomandibular disorder. Int J Surg Case Rep 2015;15:123-126. DOI: 10.1016/ j.ijscr.2015.08.036. 